\title{
I Prefer a World without Men: A Study of Language, Gender and Power in Women Writers of South Asia
}

\author{
Zainab Akram
}

Sardar Bahadur Khan Women University, Quetta Pakistan

Naheed Qasim

Sardar Bahadur Khan Women University, Quetta Pakistan

Hajira Masroor

Balochistan University of Engineering and Technology Khuzdar

Shehnaz Mehboob

Sardar Bahadur Khan Women University, Quetta Pakistan

Doi:10.5901/jesr.2015.v5n2p223

\section{Abstract}

This essay investigates the multiple issues of feminism's combat with the triple P's, phallocentric disposition, patriarchal authority, and the paterfamilias. Researchers propose to apply the Theory of Community of Practice to the feminism writings by selecting three short stories of female writers. Researcher's primary text includes Banana Yoshimoto's Newlywed from Japan; Ding Ling's When I was in Xia village from China and Krys Lee's Temporary Marriage from Korea. After analyzing the domain of language, power and gender and also exploring the community of practice theory, Researcher dig out that the three aspects in researcher research area overlap and complement each other. The gender or the community in general contributes the other gender to accept its practices. The negligence, rebel or protest result in personal isolation and rebuke from society in general. But, exceptions do arise and mark themselves according to their capacity. A remedy is possible when all the lingering threads of language, power and gender and community practices are knitted in a harmonized pattern of social and linguistic applications.

Keywords: phallocentric disposition, patriarchal authority, paterfamilias, language, gender and power.

\section{Introduction}

This essay investigates the multiple issues of feminism's combat with the triple P's, phallocentric disposition, patriarchal authority, and the paterfamilias. It focuses on three short stories by south eastern women writers of Chinese, Japanese, and Korean origin. Negotiating the contiguous areas of language, gender, and power, this essay seeks to invoke the Theory of Community of Practice as a point of departure. The theory offers a unified framework to analyze the role played by language, gender and power in the realm of South Asia and help investigate a certain sphere of a chosen geographical region. Perhaps, the immediate social circle in a specific premises take the responsibility and join hands in the responsibility of reproaching and rebuking, under dominion of certain mode of thought and domain of action which impulses explicit actions under unidentified believes and unwritten laws, especially, when the culprit and criminal is a women; no matter how un-guilty she might be.

\section{Purpose of the Study}

Researchers propose to apply the above stated theory to the feminism writings by selecting three short stories of female writers. Researchers primary text includes Banana Yoshimoto's Newlywed from Japan; Ding Ling's When I was in Xia village from China and Krys Lee's Temporary Marriage from Korea. 


\section{Research Questions}

Researcher would be concentrating on the following statements:

1. How language, gender and power complement each other?

2. How does language owe the power to rehabilitate or deteriorate its user?

3. How would the criteria of power origination and extension be settled in self or society?

4. How can the gender roles be shifted through prime effort by any of the candidate?

\section{Background of the Study}

The South Asian region fascinates researchers to explore the usage of an empowered language by the women writers to depict the gender and social injustices inflicted in various aspects to subjugate them. They try to create the difference at their own ends by portraying the sense of truth, reality and a protest in the loud and sometimes subtle feminine voice, which is perhaps only too coarse in their thoughts while fighting against the patriarchal norms of the world. The multiple linguistic resources in the practices of a given community are not only ignored but the local observations are also generalized.

The confusion arises when social and psychological foundations of language and gender are generalized. Though it's a fact, that vernacular variant is a symbol of solidarity and exemplifies women's rather than men's language. The real difficulty arises in searching for generalizations about women and men as global sociolinguistic groups, which exceeds in social practices within local communities.

As far as social practices are focused, When I was in Xia village depicts cry of the protagonist against gendered societal norms for her share in life. Newlywed fascinates me with its aspect of first person male narration. The binary of a housewife by a husband fails to out shadow her presence. Temporary Marriage depicts the limits of struggle within the power jurisdiction of a desperate mother, who is ready to meet whatever it takes to find her daughter.

The language employed in the above short stories, involves the expression of woman's power and her rebel against self and society to burst out or at least mark her presence, though she might still survive un-noticed. But the gestures are not always unavoidable, and the infinitesimal additions she continuously makes in the patriarchal world within her own capacity, are unavoidable.

The area of language, gender and power is multidimensional in itself, especially when applied to explore the realm of female domain of writings. Marginalized, cornered and victimized by the androcentric portrayal, the women upheaves from the sessility of heteronormativity, and try to voice out her inner self which is overpowered and numbed, and deprived, unheard for centuries and the binaries of gender display destitute them further into commodities and subjects.

Has gender to do anything with either language or power? Yes! And the nexus between the above three variables is very strong. Gender is being biologically male or female and sex is our expectation from each. We can say that gender is constructed and sex is given. We socialize children in these gender roles to be considered natural, inborn, intrinsic and appropriate. These gender roles change, which makes them not natural but taught.

So, in this scenario where does language come? Language constructs gender. The words, sayings, songs, jokes, and literature thus a whole lot of vocabulary define behavior of women and men in society. The words construct, convey and reinforce these expectations, are given the status of norm so a social reality is constructed.

Rehman, (2014) asserts that power can be defined in innumerable ways. It is the capacity to do things or simply a gratification or pleasure of getting obeyed. One can understand the way the world views a society empowering or disempowering others. If a society believes that the elite are honorable, everybody accept it as a non-objective obedience and as hegemony. Coined by the Italian Marxist thinker Antonio Gramsci, the term is used to explain how antifemale stereotypes are accepted by women themselves. Language brainwashes and establishes the hegemony of the ideas of the dominant group through power acceptance.

Kiesling,(1996) opines that women's and men's language are different and the fact is that men hold power in society But how and to what extent the power of men affects their speech and language is yet to be declared. Their identity as men is powerful enough to affect their language use and actively they employ language to create identities for them and the other gender. All the men create powerful identities through language usage, but their lies a specific linguistic expression of power that is differs from speaker to speaker, situation to situation, and moment to moment. Men create these specific identities through role indexing and by using linguistic forms and strategies identifying and specifying these roles in the community and culture and thus prove capable of effecting people's actions and thought process. 
The ideology of the communities organizes the world into competitive hierarchies. The role of men seats him at the top of hierarchy along with power. The larger culture ideology embeds the indigenous ideology which is hegemonic masculinity, esteeming some characteristics more than others. The characteristic that reign the hierarchy of humanity is the power of men. The identification of men with different roles in different hierarchies, builds several dominant characteristics. Power is visible in the discourse of men but leads to variation pattern in the usage of language. Globally variants have general meanings, but these general meanings become specific only when used with other social systems.

In the past years, the studies of language and gender yielded in various dimensions of language use; gender and language interaction; and connection of power to that interaction. If language is considered as assisting male dominance, it is also seen as means for women to resist oppression and pursue their interests. The social practices that produce particular forms of language and gender in communities are obscured by abstracting language and gender, distorting the ways they connect power relations to produce values and plans. A theoretical insight helps to a close look into how language and gender interact at social practices in which they are jointly produced. Language and gender cannot be treated as independent phenomena's, as the social and cognitive interactions between them would be missed. Abstraction splits the links between language and gender in the social practices of communities and thus kills the powers that exist in the links.

The concepts of women and men are taken for granted in sociolinguistics taking, in the characterizations of gender that have been explained in gender-differentiated linguistic behavior. Women's language has been said to reflect the dogmatism, esteem realization, upward mobility, insecurity, respect, growth, emotional self-expression, connection to self and others, sensitivity and solidarity. And the language of men is heard to be the evidence of their toughness, lack of passion, effectiveness, objectivity, proficiency, order and resistor. The interpretations of these assertions about women and men have been made in various times and circumstances and on diverse residents.

The divisions are actually too many to embrace and reach a solid ground of interpretation and solidarity. Gender is apart other features of social identity, the linguistic system is different from other linguistic practice, language from social action, interactions and events from community and personal history, difference and dominance from wider social practice, and both linguistic and social behavior from the communities where they occur. Once interweaved, we get an amalgamation and a plethora of diverse structures. The real men and women conceal somewhere, perhaps in the depth, too far lost in the explanations.

Sayings like women seek connection and men status in their talk could have a statistical standing within a specific community, but behavior of the actual women and men will overlap generalizations with another. If femaleness and maleness are to be discriminated from each other in characteristics like power, ambition, physical coordination, rebelliousness, caring and docility, the part of these features in generating and texturing between the core of female identities and very male identities becomes invisible.

To become language-users and gendered members in a community, indulges participation with other members in multitude practices, establishing linguistic, gender, social identities and relations simultaneously. People in a community construct a sense of themselves and of others as persons and members with authority and privilege in those communities. The interaction of language excels to dress, body adornment, ways of moving, gaze, touch, handwriting style, locales for hanging out, etc.; with the limitation to not just a gendered self, but could be unemployed, AsianAmerican, lesbian, college-educated, post-menopausal selves; serving in multiple relations to other people. It's the gender not language, which is joined with real people's contribution forms in the communities to which they belong.

A stress on mere difference of gender, neglects other factors like language and constituents of social identity. Gender could be a sex- based mode of undergoing societal traits like class, culture, age, desire, litheness, and musicality. To examine gender as just an addition to other aspects of identity would miss its significance. And only the understanding of sex shapes in language use and ignoring features of social individuality would be to paint with one eye closed. Independent segments do not part the speakers like part European American, part female, part middle-aged, part feminist, part intellectual. Theorizing gender from other social identity aspects leads to premature generalization. The way the community is defined is of chief importance in any study of language and gender.

The speech community is a loosely defined construct by the Sociolinguists which incorporated linguistic systems, norms, and social identities. The theory embrace John Gumperz' definition of a speech community which is a group of speakers, sharing rules and norms in language usage, and define the populations on the basis of location. Differences and relations among the people of these speech communities are marked in terms of abstracted characteristics like sex, age, socioeconomic class and ethnicity. And variances in ways of speaking depends on inter relation between these features and social practice.

To understand social practice and individuality in the community, Jean Lave and Etienne Wenger's notion of the 
community of practice is to be undertaken which is away from the community defined by a location or by a population. Rather, it focuses on social engagement where language serves, not the place and people.

A community of practice $(\mathrm{CoP})$ is a group of people whose ways of doing things, ways of talking, beliefs, values, power relations, practices etc. arise jointly. It is defined by its membership and the practice of the members. These could be people working together in a factory, in a bar, a neighborhood play group, a nuclear family, police partners, born and they die, any changes of membership might perish them, or closely vocalized with other communities. Individuals merge in multiple communities of practice, and multiplicity of this participation discovers individual identity. The focus is on communities of practice rather on individual as an entity floating around in social space.

The production and reproduction of gender has diverse procedures of contribution in communities of practice. Women are supposed to be subordinate to men in the workplace, do women not engage in combat in the military, in the academy, theoretical disciplines are occupied by women focused in descriptive and applied work. Umbrella communities of this sort do not offer and allow neutral membership status.

The linguistic patterns are developed by speakers while engaging in various activities of communities they participate in. The linguistic resources along with the community are fixed, and the individual's relation to the two is fixed. The linguistic form is simply given and the speaker simply learns it, uses it, mechanically or strategically and the reality is that the linguistic form is constantly and mutually constructed in social meaning, social identity, community membership, forms of participation, the full range of community practices, and in the symbolic value. This makes us adopt new ways of talking and discard some old ways, to adopt new ways of being women and men. The individual's way of speaking is a complex articulation of the individual's kind of participation in that community with participation in other communities. Gender is not constructed afresh in each interaction or each community of practice, but is needed to be understood as each community is related to other community.

The concept of $\mathrm{CoP}$ is widely accepted as it presents a learning theory, acknowledging informal networks and groups, the groups which are scattered and to face to face in contact. This theory allows learning beyond individual, between structure and agency with comprehensive details of how learning takes place. The process has some similarities and differences with other groups like discourse and speech communities as referred by Eckert (2000) and Prior (2003) respectively. Ragoff and Lave (1984) mix education with every day (shopping, skiing, workplace etc.) and stress on the importance of context in thinking, "thinking is a practical activity which is adjusted to meet the demands of the situation", (p.7).

The notion of $\mathrm{CoP}$ leads to participation in activities that guides towards learning. These activities could range from navigation to psychotherapy, and from artificial intelligence to blacksmith (Chaiklin and Lave, 1996). Holland and Lave (2001) focus more on collective identity and struggle for a social change. The concepts of the theory of CoP are slippery and elusive and rest on multiple issues like language, literacy, discourse and power (Barton \& Tusting, 2005). Greg Myers, however, demonstrates the shortcoming of the theory in terms of ambiguity of language, meaning, identities and localities (as cited in Barton \& Tusting, 2005). Cramford opines that feminist social psychology is the way to investigate gender in social relations and process (Cameron, 1998). The researchers will try to focus on female psychology in a selected social scenario, which motivates certain actions.

\section{Language, Gender and Power in Women Writers of South Asia}

\subsection{When I Was in Xia Village}

When I Was in Xia Village, by Ding Ling is a horrifying connotation about the usefulness and disposability of the female body, in several modes. A cultural example is 'a woman comrade, whose feet were 'reorganized' originally bound, and still crippled after being unbound'. Furthermore, the issue under the name of patriotism and loyalty with country is exploited by manipulating the use of a woman body for the purpose. A woman cadre author magnifies an angle of viciousness and integrity in modern Chinese literature, when Cassia, the bounded feet women, declares in the story that, 'we women really are accursed'.

The case of Zhenzhen (the name means chastity) hi lights the advent of a violence of complicated equipment that imposes agony, torment and deteriorates the victim inside out. When I Was in Xia Village signifies an expiration of virtue and a punishment to a twofold snare, initially forcefully and later as a protest and is declared as a crime in both conditions by the unprinted laws of social and patriarchal mundane, 'she's worse than a whore' and her free spirit declared as, 'that girl was always fast'.

Zhenzhen was unfortunate to face and physically receive what any Chinese women feared during wartime and 
after her rape, the mission she embraces as a prostitute-spy typifies complete loyalty and patriotism is the rebellion of self to prove strength of bearing and an attitude that what lost is the virginity, 'she can have the nerve to look anyone in the eye'. And the urge to stand up and lay ahead in the name of nation is the offering of that same body once safeguard now willfully used as a naked weapon against the enemy, 'she talks about those devils like something very ordinary'. The act of bravery within the enemy line could not be dared by any equipped soldier, rather by a delicate damsel, alone and desolate accepting the humiliation, shame and disgrace to upraise the name of country, to dirty her body with most detested profession and a filthy job, unlike uniformed male soldiers who would be honored and privileged, proudly owned by people and party for losing a leg or an arm, and still greatly reputed if they lose their life.

Zhenshen died a thousand deaths and finally medaled with a fatal disease. Unfortunately, the sacrifice seems lost and overseen, actually not comprehended as Zhenzhen's fellow villagers, ignorant of her mission, think of her otherwise and seem , 'they know more than we do here'. The villagers and women, 'proud of not having been raped', were especially contemptuous and tried to represent themselves and posed their purity and chastity in contrast with her's.

The judgment was passed that a girl like Zhenzhen who dare defied an arranged marriage, failed to safeguard her virginity is twofold detestable, is to be blamed for her misfortunes and for choosing to be a prostitute; and at the same time earning herself the title of a traitor and mounts to nothing less than outrage and disgrace, as Cassia says, "being women is a disaster'. In an era, when traditional female virtues and chastity was still worshipped, and the act of sleeping with the Japanese soldiers, no matter if she is a spy for the Chinese, was horribly frowned upon. Meanwhile, Zhenzhen suffers submissively, her venereal disease medaled as a physical token of both patriotic passion and her unredeemable humiliation, 'her troubles were not only physical'.

Feminist critics argue that Zhenzhen's story indicates equally the cruelty of the Japanese invaders and the insensitivity of Chinese defense forces. The sufferings of Zhenzhen's sufferings are wholly targeting only the women with arranged marriage, rape by enemy soldiers, exploitation of her body by both armies and worse of all, after her return to the village in search of a homely embrace and consolation from her own people; instead she is welcomed with banishment for violating the chastity code. A paradox stages Zhenzhen's story, that she can achieve self-esteem only through deliberate self-abandon. Zhenzhen hails to the secret mission at the call of the Communist United Front. In the pious cause of liberating the collective body of the Chinese, she offers her own body to be ruined by the enemies. But back home, the same lot of people that she vowed to save, banish her, in response to the most unliberated chastity law of people.

Surprisingly, the corporeal ailment and physical agonies she underwent, Zhenzhen appeared a healthy and glowing person. As the narrator witnessed, 'There was no outward sign of her disease'. Her complexion was ruddy. Her voice was clear. She showed no signs of inhibition or rudeness. She did not exaggerate. She gave the impression that she had never had any complaints or sad thoughts. The saintly self-control and forbearance to the painful experience, perhaps is the veil to the painful experience. Her physical hidden deterioration is stronger than her devout commitment, denoting her power and determination still to live and heal.

The language the author used in depicting Zhenzhen's natural, healthy look is a foil, a wrap to hide a body which is rapidly deteriorating, 'Have I changed?' says it all. The contrast between how Zhenzhen's body looks and how it feels, is a symptom of a reality or realism that turns against itself in ignoring the fact that it's only the hegemonies standard of a gendered community which fails to neglect the act of a female body, no matter for whatever purpose, at the cost of the spiritual attributes.

Ding Ling's thoughts and language are powerful enough to blame numerous societal standards and phallocentric forces of reality: the Nationalist regime and the Japanese invaders. She cannot appreciate the power of justice ruled by gender discriminations and laws resting on false pedestals of modesty. A free-spirited girl, who had the power to oppose a prearranged marriage, should be considered a virtue in the new society. Zhenzhen had been commoditized twice; she was raped by the Japanese and she is convinced to sacrifice her body for her party and nation on the account that once her virginity is lost. Still later, she declares it was her own free will and she does not stand hatred or regret against anyone.

For medical treatment and rehabilitation, Zhenzhen would finally go to another city, but the query remains: Would the inglorious past, as a raped woman and a Japanese army prostitute, not haunt her and be treated? She searched for rehabilitation and revival in her village and she received a shock build on gender discernment, particularly being a women, 'she's only a human... even better looking'. Zhenzhen might end up spending the rest of her life undergoing the cycle of political and social illness and rehabilitation.

However, the author brings a relief in this phallocentric society, when she depicts ZhenZhen's past lover, Xia Dabao, indifferent to these typical women and men. ZhenZhen loved him too, and tried to run away to become a nun, as 
the only way to avoid the arranged marriage her father had set up for her, when she was captured by the Japanese. Xia remorse her fate and felt as if he had been the reason she had been captured. Now, ZhenZhen's family approved of him marrying her after she had returned because he would be the only marriage proposal she would receive. No man would willingly marry a woman made impure by the enemy and Xia offer testifies that they had been in love.

ZhenZhen could not marry her love and stay in the village of her past. The narrator told her that "when the end of a road is reached, one must turn," but at the turn what she decided to take is different from what everyone had expected from her. She knew ways were to be parted, as she become an outsider in her village and must have a restart of her life far from that place where one man was ready with truth and acceptance to hold her, but the poisonous arrows of detestation were unavoidable.

ZhenZhen's eyes had a spark of life and enthusiasm. She had hardened and numbed herself during her suffering, forced herself on without much thought, and in the village she was surrounded among the numbed state of mind. She needed to be among strangers, and be healed of the disease she had contracted if she wanted to restart her new life with a new identity.

She had told the author that among the enemy she 'somehow had to find a way to survive, and if at all possible, to live a life that was meaningful'.

The dual aspects of the Japanese resentment and the importance of tradition along with a sense of hope are depicted in ZhenZhen, who had the power to bear her fate. 'Cassia burst into tears, and it was ZhenZhen who had to comfort her'. She was done with the Japanese; she shamed her parents by refusing an arranged marriage and later refused Xia which was her last chance of being accepted by her village. She broke the gender laws by feeling that she will relive, and study, same as, 'Japanese women are all good readers. All those bloody soldiers carry beautifully written letters about them...from wives or girlfriends.

\subsection{Yoshimoto's Newlywed}

Yoshimoto Banana, the Japanese author's collection of shorts stories Lizard, 1993, presents NewlyWed. The interesting aspect about the story is that it is told from a male perspective. Banana does not make much of an effort to simulate a male voice along with the thought, the language, the depiction of ideas and perspective is androcentric. The tone is so much intoned into a phallocentric protagonist, that an encounter with the kind of young, passionate female narrator seems evitable.

Newlywed is a paranormal story with strong magic realism, told in the first person by a newly married man about a very strange experience he faced in the train in Tokyo. Yoshimoto's writing is significant because it is a departure from traditional Japanese literature, where young characters live in a consumer society cut off from traditional social structures like the family, work and marriage utilizing non-literary language, with the changing roles of women in Japanese society, a freedom to go with the world on their own terms, who enjoy an economic power exceptional in the lives of their parents. The submissive Japanese female notion is challenged in Yoshimoto's fiction not aggressively but through a refusal to accept adult roles. The world of the corporate male is mocked in which women are traditionally regarded as little more than wallflowers.

The key themes of loss, death and finding a new way of being, using language and techniques borrowed from popular culture, an interest in healing, searching for spiritual meaning and a reconnection with nature has an added significance at a time of the breakdown of community and family structure; she explores spiritual themes in the absence of explicit descriptions of sexuality. Yoshimoto's persistent search for meaning in the lives of her characters failed to be provided by either the traditional Japanese family. As a literature of self-help, Yoshimoto's characters turn inwards, summoning their strength from within, connecting with the natural and the supernatural worlds.

Her success is forcing not just an awareness of the changing gender roles in contemporary Japanese society but the rigidly and ideals of femininity or ryôsai kenbo (good wife, wise mother), a term coined by Nakamura Masanao in 1875, emphasizing the woman's role within the family, undergo a change. If ryôsai kenbo represents an ideal of femininity, emphasizing a woman's role within the family, the rise of the modan ga-ru (modern girl) represents the opposite, with young Japanese women wearing western dress and hair styles and smoking cigarettes in public. In 1924, Kitazawa Shuichi described the Modern Girl as being 'apolitical', neither being an advocate for women's rights nor of having any intention of being a slave for men (as cited in Silverberg, 1991, p.240). Yoshimoto's characters initially suffer the loss of family or a loved one, when suffering leads to discovery of fulfillment. The role of housewife is still central in many people's thinking in Japan about women and their place in Japanese society, but Yoshimoto steps outside existing literary and social conventions to explore new 'ideals of femininity' using the language of her peers. Yoshimoto upholds 
traditional institutions like marriage and family to empowering and identify strong female protagonists who 'speak out without fear of ostracism'. Yoshimoto has liberated her characters from past struggles and gave her female characters freedom.

In this story, the characters face tremendous suffering to reach healing and spirituality, and struggle to make sense of an increasingly alienating world and thus leading to a global culture. Yoshimoto is clearly interested in exploring issues like marriage, children, relationships, sex, death and spirituality, leading to Global literature. She has shifted her interest beyond the confines of the enclosed shôjo world to explore a wider range of social issues such as the dangers like domestic and sexual violence and the environment. Living in big cities is clearly seen to contribute to the pressure and stress suffered by Yoshimoto's characters.

In Newly Wed, the sex is substituted with spirituality. The English translation of the story Newlywed in 1995, presents the narrator in a drunken state on the train one night, when he discovers that his home is so 'happy' that it 'makes me want to puke'. The protagonist begins to feel very down about his new marriage and has problems with his new wife, 'and had been married to Atsoko for about a month' still 'drinking whiskey at a bar with my buddies'.

The breakthrough in Yoshimoto's writing is to reconstruct the power of family and the relation of self and selfconsciousness and self and strangers. The narrator of the story says of his wife Atsuko, 'Sometimes I feel like I'm living with the quintessential housewife. I mean, all she talks about is our home'. It is for this reason that he utters,'...frozen in my seat...I stayed on the train, because I didn't really feel like going home'.

The power of the story is its blend of real and unreal. The power of language depicts the intensity of feelings, 'doors again closed...for all eternity' and the passions turning cold as, 'dark of the night'. Yoshimoto talks of power from within the mind and the subconscious. On one hand, there is the depiction of realistic activities in life and on the other hand, her story speaks of supernatural forces. The powerful connections among family, unusual relationships, supernatural elements and healing, along with the city life of young generation, sufferings of ordinary people which empowers them towards the journey to solve the catastrophes and enable themselves to express the experiences and break away from the sorrow bondage.

The narrator in Newlywed, lost in bustle of Tokyo, under the work pressures, fails to preserve the family ties, relishing good old times, but not reliving them. Newlywed depicts Yuichis androgynous concept of human being seen as an organic whole, large enough to comprehend man in some and woman in other areas.

The secondary character in the story is a woman, the fantasy woman, the only a figment of the main character's imagination. Described in the complete exotic beauty, typical of androcentric depiction, 'I couldn't even tell what country she was from. She had long brown hair, grey eyes, gorgeous legs...flowers, right over her ample breasts'. The familiarity he senses with the lady is described in terms of specific gender roles in heteronormative context, 'I definitely knew that face from somewhere - like maybe she was my favorite actress, or my first girlfriend, or a cousin, or my mother, her face looked very familiar'.

When the woman first appears to the narrator as an old beggar, he blatantly ignores the old man and seems happy to be engaged in conversation with the mysterious beauty and is willing to confess his inner world to her, though strange, but a moment of sensuous pleasure associated with gender and phallic overcame but overwhelmed him simultaneously when the question raised by both was the same, 'I suppose there's some good reason why you don't want to go home'. A response inevitable of male gender aroused with, 'a warm fragrance of a women's skin', was felt by the narrator. The perfect stranger woman helps or rather is allowed to ease the pain, as she says, 'I wonder if you'll change your mind when you see me like this', contrary to the social and marriage bonds and is willfully allowed to tempt the narrator in stepping out of his confined routine and realize the perfect woman, his wife in his life.

Later, when the narrator in the position of virtual death, assumes that he himself would never return to his familiar life, he discovers that his new wife Atsuko is actually a perfect woman. He had failed to appreciate the perfection in her. She, 'sings in the bath and she talks to her stuffed animals while she is dusting them. On the phone with her friends, she laughs hard at anything they say'. The realization is subtle and quiet to a powerful and strong impact Atsuko is trying to make in the life of her husband by voicelessly fulfilling the tasks and un thanked by the husband. Finally the words uttered by the narrator are, 'Thanks to Atsuko's ways, we have a happy home'. The fact is this is not such a happy home. Atsuko is extremely struggling to make everything perfect and fails to realize that her husband does not feel comfortable with the perfect life style.

Atsuko is a binary to the apparent power of a whore, but even in a seemingly powerless position she manages to conquer over her husband's possession. The power of thought can transform the world of comfort into one of an alien. But a change in life brings freshness to fascinate. He gets a better understanding of Atsuko's perfection, 'she never forgets to put a fresh bowl of rice on the family alter every day. When I wake up on Sunday mornings, shell be doing 
laundry, or vacuuming, or chatting with the lady next door. Every day she puts out food for the neighborhood cats, and she cries when she watches mushy TV shows'. Discovering this new value in his life is a crucial part of his mental healing, 'encountering something much larger as myself', but the mental disease of phallocentric can never subjugate itself. It appears with a vigor to denounce the other gender at every turn, as the narrator's utterance to the lady in train that, 'an attraction for body, but not for person, I can picture that? How could you?'. Ironically, the narrator learns to look from different angles at Atsuko, who had turned, 'a tiny black line', through fantastic encounters of the fantasy woman, 'What better way to catch your eye?' was a willful attraction towards a timely entertainment, a strait jacket phallic attitude which leads him to Atsuko. The resentment of one gender to other is described as, 'It's not any language from any one country. They are just words'. The language for phallic power of gender and the right to leisurely astray oneself, simply goes as, 'that's the way it is when you first get married...'

The experience of the language-gender might be different in the different communities, where people participate at a given time or at different stages of their lives. To use Mrs. Jack may be important to emphasize her subordination to a husband and to deny her individual identity. Or maybe, acquiring a new name of Mrs. John Smith upon marriage may have worked forty years ago for the young Joan Doe as a symbol of achieving an adult rank of a married woman. And the woman who patiently bears Mary with a smile from a young daughter of her employer may insist in her local residential community on Mrs. Jack from her own daughter's friends.

\subsection{Lee's Temporary Marriage}

The Temporary marriage is a journey from submission to power of decision and finally realization of the limits of that power. Mrs. Shin is still carrying the identity of her ex-husband, 'even after the shame of her husband's departure five years ago'. And the solidarity and ego compelled her to, 'behaved like the fashion designer she was'. Krys Lee shows the power shift when Mrs. Shin, '...gave her the appearance of confidence.... she had not allowed herself public displays of grief', and her strongly declaring that, 'I am not looking for a real husband... I prefer a world without men', but the women inside her insists to play the gendered role when she was, 'mortified to see a man in the kitchen'.

The display of strong language describes the strong intentions and the power of gender to possess the supremacy. But the truth is concealed in, 'Mrs. Shin had subordinated herself to her husband's will and accepted all blame when she remained childless the first six years of marriage' and, 'her husband lifted her by the start of her black hair'.

After playing successfully slipper warmer, it was time to enter a contract marriage to find her lost daughter, and she encounters a man who, unconventionally, utters, 'I live for my boys', with an extra ordinary odor, 'the smells around him would be the clean, honest smells of chemicals...'. We feel the strength of a mother, who is powerful enough to confront the stranger in a sham marriage with whom she would, 'share the common space, nothing more', and the future, the harbinger of uncertainty, 'Yes, it is a new home for me, isn't it?'.

The internal conflict is well depicted by Lee by using the powerful language of a woman to depict the powerlessness she feels, 'she did not want to look at him, understanding that she was aware of him as a man that gave him an immediate advantage over her.' The powerlessness is somehow displayed when Mrs. Shin, 'remained on her knees, 'you should slap me,' she said. She offered him her body. 'I would never hurt a woman'. He wanted to hit her, she could tell; his hands were balled into bony fists, 'You're angry', her entire body was prepared. She leaned towards him. 'You'll feel better after'.

The above action is contradictory to the woman we meet in the start that reacted when, 'his garlicky breath scraped her nose', and the declaration that, 'she was free from herself'. A momentary sense of freedom is swapped with the heteronormative rule of gender power. The language has the power to depict the limitations aroused by the subjection of paying the price of being a woman, 'it was night; it was day; it was America, it was Korea; it was nowhere and she was no one.' Mr. Rhee's compassion, however compelled her to feel, ' it was as if another her was married again with an actual future ahead, as if there was the possibility of love', and as her, 'aging body still betraying herself with its monstrous desires'.

The unfortunate meeting with her daughter is a curse and a satire to all her struggles substantiating unrewarding. The apparent powerful, composed and determined Mrs. Shin submits to her gender limitations of submissiveness and powerlessness. She injures her thighs with scissors in despair and wounds her ego. The language used by Krys Lee at this moment depicts the broken women subjugated and torn in front of her vain struggles, and 'she took off her thin belt, and tried it against her back. She was becoming herself again, loving herself...Mr. Lee crawled through...Mrs. Shin, my daring, my love, her wounded body continued her ancient story.' 
Hang (2009), opines that the attention in gender construction is paid in Literature and the extent of gender identification is affects access to power through speech and power, thus allowing a new interpretation of the gender construction. Fan (1996), extends the idea by saying that, "as language constructs reality, it perpetuates the devaluation of women; but it also provides a means by which this devaluation can be overcome" (p.95). Interestingly, in the above discussed short stories, the main male characters play an unconventional heteronomous role against the females. Ranging from Mr. Rhee to Xia and the narrator in the Newlywed, the males are the exceptional cases in the heteronormative regime of the patriarchal realm. Mr. Rhee resists hurting Mrs. Shin despite his phallic dominance. He rushes to safe guard Mrs. Shin from the haunts and dangers of New York. He attempts to break door of recluse, Mrs. Shin would have enclosed her into, and rescues her from further physical and mental damages.

$\mathrm{Xia}$, is the beacon of remorse of the crime he was not indulged into happening. His love, regard, passion, 'an honest face', and the power of rescuing a soul, which is torn and worn out physically, is a heroic deed, and a sincere effort to embrace one against the taboos and scorns of the society. The third character, the narrator, tried to escape from the conventional, draining, monotonous role his wife was playing with sincerity to knit the comfortable and cozy web of love and passion. His encounter with his inner self helps him realize the struggles of his wife in a subtle and steady manner trying to change house into home. He was about to play the typical role of practicing his supreme power, permitted by the societal norms to exhibit his patriarchal privilege, by not only in ignoring his better half but also in involving in sensuous actions.

Gender is diagnosed differently in communities of practice. The class, age, ethnicity and sex of people are related to their needs, interest, and exposure. Working class people as compared to middle class people are members of unions, bowling teams, close-knit neighborhoods. Upper middle class people are members of tennis clubs, orchestras, and professional organizations. Men are members of football teams, armies and boards of directors. Women are members of secretarial pools, aerobics classes, and consciousness raising groups. The people are capable of articulating their multiple memberships differently.

The gender roles specified in my selection of short stories, are typified for females, set by the certain mode of thought, molded in the immemorial time, by the non-published but believed and worshipped and practiced norms, unquestioned for centuries. These concrete androcentric archetypes, are tremor and turmoil by the occasional revolt against acceptance and practice by the stake holders of male gender in surprising provision, acceptance and favor of the opposite gender.

\section{Findings}

Language, power and gender do compliment and support each other, one or the other way. It's the triangle of mutual sustenance and reliance over one another. With or without power, the language and gender are automatically elevated or depressed. In When I was in Xia Village, Zhenzhen was denied the power of gender by the community of practice laws, but her language revived the power of gender, though the power is restricted her only. In Temporary marriage, Mrs. Shin was deprived of gender power by offering her body, and language power in the end, but her power of mind and ego will sort things out for her. In Newlywed, the binary expressed Atsuko was denied power of language but her power of gender could not be ignored.

The second question related to the origin and extension of power. In When I was in Xia village, the power is originated and extended through the villagers, but ZhenZhen within her capacity puts an end to that extension by quitting the village itself. In Temporary Marriage, power for Mr. Rhee is extended by Mrs. Shin, but refused by Mr. Rhee. Atsuko's presence puts an end to the extension of the power which was about to be exhibited by the narrator.

As to the question of gender role shifting, it is not possible. The limitations and societal norms check the shuffling and forbid the happening. In above discussed stories, the females observe their specific gender roles and do not cross the boundaries practiced by the communities.

\section{Conclusion}

In the capacity of language, gender and power, the community of practice theory reinforced my essay and supported my analysis of three short stories by female writers in the South Asian regions of China, Japan and Korea. Researchers particularly interest to explore the three P's in the realm of phallocentric disposition, patriarchal authority, and the paterfamilias, in relevancy to the survival of the other gender in terms of rebel, protest or acceptance of code of conduct and observance of norms and unwritten and undescribed rules, was the center of focus. 
After analyzing the domain of language, power and gender and also exploring the community of practice theory, Researcher dig out that the three aspects in researcher research area overlap and complement each other. The gender or the community in general contributes the other gender to accept its practices. The negligence, rebel or protest result in personal isolation and rebuke from society in general. But, exceptions do arise and mark themselves according to their capacity.

A remedy is possible when all the lingering threads of language, power and gender and community practices are knitted in a harmonized pattern of social and linguistic applications. The social and political responsibility of comprehension of bias, racism, exclusivity and heterosexism, is needed to be yoked in one unit. The motto, to think practically and look locally, helps shun assumptions that gender is independent of other aspects of social identity and relations, and is similar across communities with the shared linguistic meaning.

\section{References}

Banana,Y. (1995). Drifting .198 Sherif, Ann, tr., Newlywed in Lizard. New York: Washington Square Press

Barton, David \& Karin Tusting, Karin.Eds. (2005).Beyond Communities of Practice: Language Power and Social Context. Cambridge University press

Cameron,D. (1998). Gender, Language, and Discourse: A Review Essay. Signs, Vol. 23, No. 4, p g. 945-973

Chaiklin,S. \& J. Lave. (1996).Understanding Practice: Perspectives on Activity and Context. Cambridge:Cambridge University Press

Dr Tariq Rahman. (2013). Language, gender and power. Retrieved from tribune.com.pk/story/636342/language-gender-and-power/

Eckert,P. (2000). Linguistic Variation as Social Practice. Oxford: Blackwell

Eckert,P.\&S.McConnell-Ginet.(1992). Think practically and look locally: Language and gender as community-based practice. Annual review of anthropology, 1992 - JSTOR

Fan, C.C. (1996). Language, Gender, and Chinese Culture. International Journal of Politics, Culture, and Society, Vol. 10, No. 1, pp. 95114

Hang, Krista.V.F. (2009). The Heart of the Party: Language, Gender, and Power in "Tracks in the Snowy Forest". Retrieved on 1st July 2014 from: Modern Chinese Literature and Culture, Vol. 21, No. 1 (SPRING, 2009), pp. 72-101

Holland,G \& J.Lave .Eds.(2001). History in Person: Enduring Struggles, Contentuous Practice, Intimate Identities.Santa Fe: The School of American Research Press

Kiesling, S. F. (1996). Language, gender, and power in fraternity men's discourse (Doctoral dissertation, Georgetown University)

Lave, Jean. \& Wenger, Etienne (1991). Situated learning: legitimate peripheral participation. New York: Cambridge University Press

Lave, Jean \& Wenger, Etienne. (2004). The concept of a Community of Practice (CoP). Retrieved on 22nd June 2014 from: www.nwlink.com/ donclark/history_knowledge/wenger.html

Patrick, PL. (2002). Speech Community. Retrieved on 22nd June 2014 from:orb.essex.ac.uk/lg/lg232/SpeechComDefs.html

Prior, P. (2003). Are communities of practice really an alternative to discourse communities? Paper presented at American Association for Applied Linguistics Annual Meeting, Arlington, Virginia. 22 to 25th March, 2003

Rogoff, B. \& J. Lave. (1984). Everyday Cognition:Its Development in Social Context. Cambridge, MA: Harward Uni. Press

Silverberg, Miriam.(1991).'The Modern Girl as Militant.' In Gail Lee Rosenberg (Ed.) Recreating the Japanese Women, 1600 - 1945. Honolulu: University of Hawaii Press

Wenger, Etienne. (1990). Toward a theory of cultural transparency. Palo Alto: Institute for Research on Learning , Communities of Practice. Cambridge University Press 